\title{
HIGH PRESSURE STEAM OXIDATION OF NI-BASE SUPERALLOYS IN ADVANCED ULTRA-SUPERCRITICAL STEAM BOILERS AND TURBINES
}

\author{
Gordon R. Holcomb \\ National Energy Technology Laboratory, 1450 Queen Ave SW, Albany, OR 97321, USA \\ Keywords: Steam, Oxidation, Superalloy, Pressure, Advanced Ultra-supercritical
}

\begin{abstract}
This research is to support efforts to design and build safe and cost-effective advanced ultrasupercritical (A-USC) steam boilers and turbines, with increases in energy production efficiency and reductions in emissions, including $\mathrm{CO}_{2}$. A 1 liter flowing steam autoclave, rated to 346 bar $/ 704^{\circ} \mathrm{C}$ and $228 \mathrm{bar} / 760^{\circ} \mathrm{C}$, was constructed and the first steam oxidation test conducted at $267 \pm 17$ bar and $670^{\circ} \mathrm{C}$ for $293 \mathrm{hr}$. A comparison test was run at 1 bar. Parabolic rate constants, $\mathrm{k}_{\mathrm{p}}$, were estimated from mass change data and compared with literature values from longer duration tests - but none at this high of combined temperature and pressure. Test materials were Ni-base alloys H230, H263, H282, IN617, IN625 and IN740. At 267 bar H230, H263, H282, IN617 and IN740 had increased scale thickness and $k_{p}$ values a factor of one-to-two orders of magnitude higher than at 1 bar. The 1 bar data matched literature values for chromia, while the 267 bar data had a higher oxidation rate. IN625 had a four order of magnitude increase in $k_{p}$ at 267 bar compared to 1 bar. Possible causes for increased oxidation rates with increased pressure were examined. Increased solid state diffusion within the oxide scale is quantifiable and accounts for a modest increases in expected corrosion rate and scale thickness. Increased amounts of hydrogen in the alloy, injected into the metal during steam oxidation at high pressures, can increase oxygen permeability and thus lower the ability of the alloy to establish a chromia scale-an increase in the critical $\mathrm{Cr}$ content for chromia scales.
\end{abstract}

\section{Introduction}

Goals of the U.S. Department of Energy's Office of Fossil Energy program include power generation from coal with efficiencies over 60\% [1]. Increased net plant efficiencies towards that goal, to over $45 \%$ (in terms of higher heating value, HHV), can be realized with the use of steam boiler conditions of $1300-1400^{\circ} \mathrm{F}\left(704-760^{\circ} \mathrm{C}\right)$ and $4000-5000$ psi $(27.6-34.5 \mathrm{MPa}, 276-$ 345 bar), so-called advanced ultra-supercritical steam (A-USC) conditions [2]. Improved efficiencies will also reduce emissions, include $\mathrm{CO}_{2}$. This research is in support of efforts to design and build safe and cost-effective A-USC steam boilers and turbines.

A few comments on nomenclature are in order. Unless otherwise noted, pressures in this communication are reported in absolute terms and not gauge pressure (i.e., psia and not psig). The pressures and temperatures of a pulverized coal (PC) power plant are commonly reported as in this example for the Isogo 1 ultra-supercritical pulverized coal plant: $4060 \mathrm{psi} / 1050^{\circ} \mathrm{F} / 1110^{\circ} \mathrm{F}$ $\left(280 \mathrm{bar} / 566^{\circ} \mathrm{C} / 599^{\circ} \mathrm{C}\right)$ [3]. The pressure and first temperature refer to conditions in superheater tubing and the inlet of the high pressure turbine; the second temperature refers to conditions in the reheater tubing and inlet of the intermediate pressure turbine. The terms subcritical, 
supercritical (SC), ultra-supercritical (USC), and advanced ultra-supercritical (A-USC) refer to the pressure and temperature of the superheater and inlet of the high pressure turbine. While there are no universally accepted definitions of these terms, they arise out of power plant design and the alloy categories required for operation. Table I shows one set of definitions for the steam conditions for each, along with typical net plant efficiency. Nickel-base superalloys are required for A-USC pulverized coal power plants. The U.S. convention for net plant efficiency calculations is to use higher heating value (HHV), which includes the heat of steam condensation. The European convention is to use lower heating value (LHV), which does not include the heat of steam condensation-resulting in higher reported efficiencies [2].

Table I. Steam conditions and net plant efficiencies for various categories of pulverized coal power plants (adapted from ref [2]).

\begin{tabular}{ccc}
\hline Nomenclature & Conditions & $\begin{array}{c}\text { Net Plant Efficiency } \\
(\mathrm{HHV})\end{array}$ \\
\hline Subcritical & $2400 \mathrm{psi} / 1050^{\circ} \mathrm{F} / 1050^{\circ} \mathrm{F}$ & $35 \%$ \\
& $\left(165 \mathrm{bar} / 566^{\circ} \mathrm{C} / 566^{\circ} \mathrm{C}\right)$ & \\
Supercritical (SC) & $3600 \mathrm{psi} / 1050^{\circ} \mathrm{F} / 1075^{\circ} \mathrm{F}$ & $38 \%$ \\
& $\left.248 \mathrm{bar} / 566^{\circ} \mathrm{C} / 579^{\circ} \mathrm{C}\right)$ & \\
Ultra-Supercritical (USC) & $>3600 \mathrm{psi} / 1100^{\circ} \mathrm{F} / 1150^{\circ} \mathrm{F}$ & \\
& $\left(>248 \mathrm{bar} / 593^{\circ} \mathrm{C} / 621^{\circ} \mathrm{C}\right)$ & $>45 \%$ \\
Advanced Ultra-Supercritical (A- & $4000-5000 \mathrm{psi} / 1300-1400^{\circ} \mathrm{F}$ & \\
USC) & $\left(276-345 \mathrm{bar} / 704-760^{\circ} \mathrm{C}\right)$ &
\end{tabular}

The purpose of this communication is to present initial results from a newly constructed and operational autoclave used for high pressure steam oxidation studies. A description of the autoclave and experimental procedures is given. Then the results of the first high pressure steam oxidation test $\left(293 \mathrm{hr}\right.$ at $670^{\circ} \mathrm{C} / 267 \mathrm{bar}$ ) is given and compared to an atmospheric pressure test $\left(293 \mathrm{hr}\right.$ at $670^{\circ} \mathrm{C} / 1 \mathrm{bar}$ ). These initial results are discussed in comparison with literature values of tests in steam at atmospheric and elevated pressures. The tests in the literature are all at lower pressures (for this temperature).

\section{Autoclave System Description}

The 1 liter autoclave was constructed out of Ni-base superalloy H230, and is ASME rated at 346 bar $/ 704^{\circ} \mathrm{C}$ and $228 \mathrm{bar} / 760^{\circ} \mathrm{C}$. It is a flowing steam system with flow controlled at the inlet with a high pressure pump and pressure controlled at the outlet with a back pressure regulator. Temperature is controlled with a thermocouple located at the outer shell of the autoclave.

\section{$\underline{\text { Water Path }}$}

Deionized water is dearated and used as feed water for the system, Fig. 1. A high pressure pump injects feedwater into the pressure lines with flow rates between 1 and $12 \mathrm{~g} / \mathrm{min}$. The water temperature is increased in a preheat furnace and then fed into the autoclave inlet, Fig. 2 . The inlet tube extends through the autoclave head to near the bottom of the autoclave. Water leaves the autoclave from the autoclave head and is cooled with a tube-in-tube heat exchanger. Pressure relief valves are located after the heat exchanger. A back pressure regulator then steps the pressure down to atmospheric. 


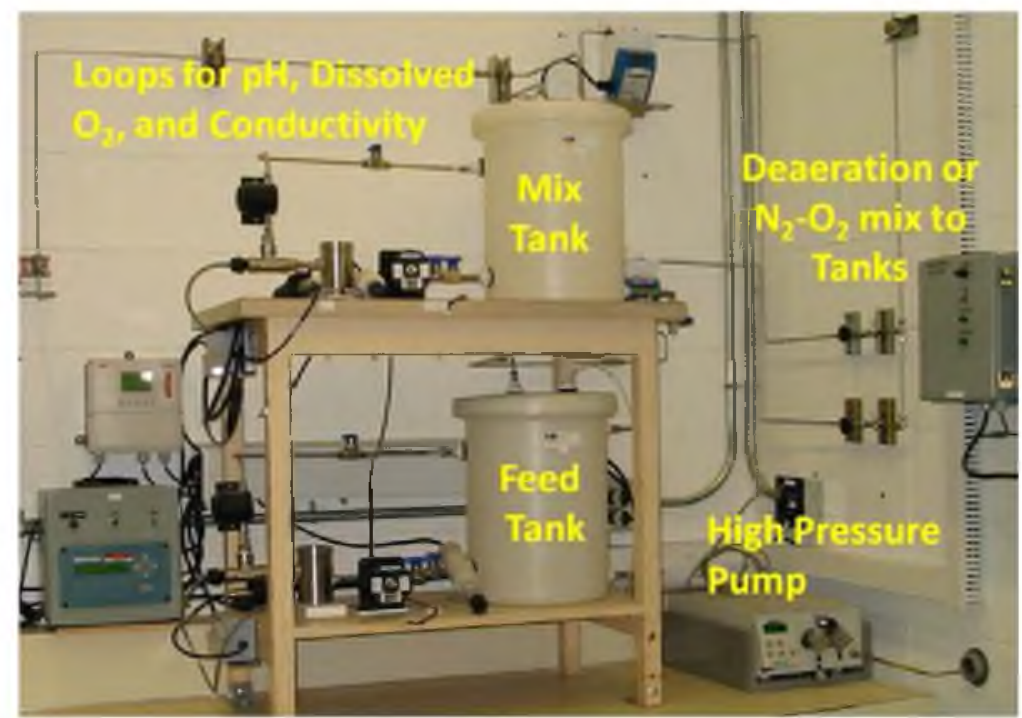

Figure 1. Feedwater preparation and high pressure pump.
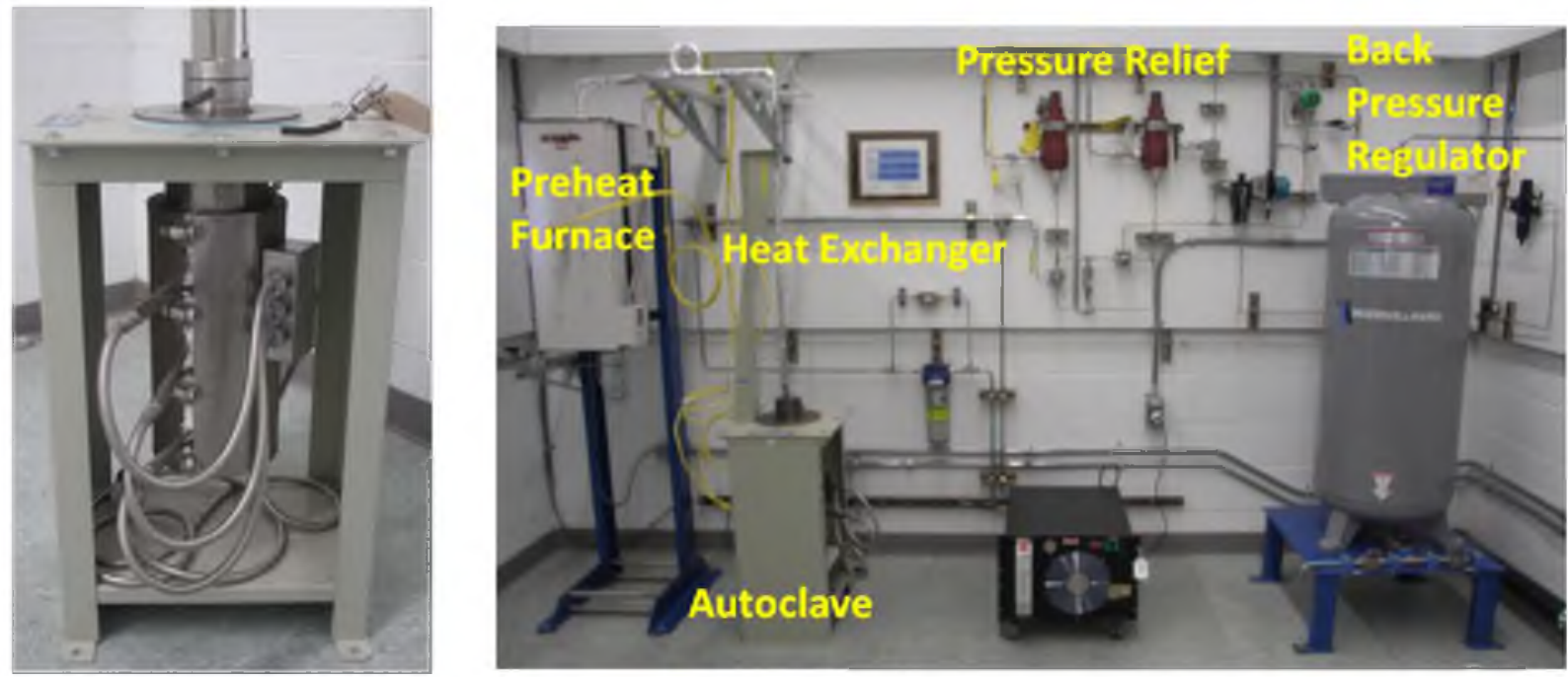

Figure 2. Autoclave (left) and high pressure water components (right).

\section{$\underline{\text { Test Startup }}$}

At the start of a test, up to 27 samples are hung from three columns of IN617 hooks welded to the steam inlet tube within the autoclave, Fig 3. After the autoclave is closed and sealed, helium is used to purge the system of oxygen with a minimum of six cycles of $60 \mathrm{psi}$ He followed by releases of pressure to near atmospheric. The pressure of the back pressure regulator is set, and water is fed into the autoclave at a rate of $10-12 \mathrm{~g} / \mathrm{min}$. The preheat furnace and autoclave heater are turned on and the temperature is ramped up to temperature. Once the pressure approaches or reaches the back pressure regulator setting, the flow rate of inlet water is reduced to the desired level for the test. 


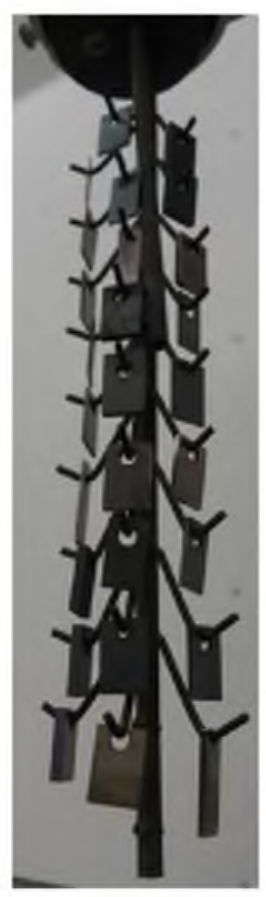

Figure 3. Samples on hooks for insertion into autoclave.

\section{$\underline{\text { Test End }}$}

At the end of a test, the preheat furnace, autoclave heater, and high pressure pump are switched off. The pressure is incrementally released by toggling the remotely activated valve open and closed. Once the autoclave pressure approaches atmospheric, helium is introduced into the autoclave and allowed to flow while the autoclave cools.

\section{Baseline Metrics-Pressure}

Trials established that the pressure could be set to within $78 \mathrm{psi}$ (5.4 bar) of the target pressure, and held with an average standard deviation of \pm 24 psi ( $1.7 \mathrm{bar})$.

\section{$\underline{\text { Baseline Metrics-Temperature }}$}

Autoclave temperature is controlled and measured with thermocouples located between the heating mantle and the outer surface of the autoclave. Actual steam temperature is cooler than the control temperature due to heat losses: conduction losses at the insulated top and bottom of the autoclave, and convection losses from the slowly moving steam exiting the autoclave top. The difference in actual and measured temperature was established at temperatures below the critical point of water $\left(374^{\circ} \mathrm{C}\right)$ by setting the autoclave pressure and then slowly increasing the temperature $\left(6^{\circ} \mathrm{C} / \mathrm{hr}\right)$ through the boiling point. Time periods of constant temperature indicated the boiling temperature. The difference in actual and measured temperature was $25^{\circ} \mathrm{C} \pm 3^{\circ} \mathrm{C}$ and was not a function of temperature, at least in the steam temperature range of 250 to $372^{\circ} \mathrm{C}$. Thus oxidation test temperatures are reported as $25^{\circ} \mathrm{C}$ less than the outer shell temperature. 


\section{Experimental Procedures}

Two steam oxidation tests were conducted - one at high pressure and one at atmospheric pressure. The atmospheric pressure test was designed to mimic the time and temperatures of the high pressure test. Six alloys were examined, with compositions as shown in Table II.

Table II. Compositions of alloys (wt $\%$ ) measured by $\mathrm{x}$-ray fluorescence; interstitials such as $\mathrm{C}$ and $\mathrm{B}$ were not measured.

\begin{tabular}{lrrrrrrrrrrr}
\hline Alloy & $\mathrm{Fe}$ & $\mathrm{Cr}$ & $\mathrm{Ni}$ & $\mathrm{Co}$ & $\mathrm{Mo}$ & $\mathrm{Si}$ & $\mathrm{Ti}$ & $\mathrm{Al}$ & $\mathrm{Mn}$ & $\mathrm{Nb}$ & Other \\
\hline H230 & 0.4 & 22.2 & Bal & 0.3 & 1.3 & 0.4 & & 0.4 & 0.5 & & $14.4 \mathrm{~W}$ \\
H263 & & 20.0 & Bal & 20.1 & 5.7 & 0.3 & 2.1 & 0.3 & 0.5 & 0.1 & \\
H282 & 0.2 & 19.3 & Bal & 10.1 & 8.4 & 0.2 & 2.1 & 1.3 & 0.1 & & \\
IN617 & 0.4 & 21.9 & Bal & 11.5 & 9.6 & 0.02 & 0.5 & 0.9 & 0.04 & & \\
IN625 & 4.4 & 21.4 & Bal & 0.1 & 8.4 & 0.3 & 0.3 & 0.2 & 0.1 & 3.3 & $0.3 \mathrm{Cu}$ \\
IN740 & 0.8 & 24.3 & Bal & 19.6 & 0.5 & 0.8 & 1.7 & 0.7 & 0.3 & 1.9 & \\
\hline
\end{tabular}

Samples were nominally $0.75 \mathrm{in} \times 0.5 \mathrm{in} \times 0.1$ in $(19 \mathrm{~mm} \times 13 \mathrm{~mm} \times 2.5 \mathrm{~mm})$ in dimension with a 0.125 in $(3 \mathrm{~mm})$ hole near one edge. Surfaces were ground to a 600 grit finish. Triplicate samples were exposed in the high pressure test. One specimen of each alloy was exposed in the atmospheric pressure test. The high pressure samples were hung from three columns of IN617 hooks (Fig. 3) - placed in a staggered arraignment. Atmospheric pressure samples were stood up in a tilted fashion in small alumina crucibles, such that none of the six sample sides were flush against the crucible.

The total time at $670^{\circ} \mathrm{C}$ was 293 hours, with a pressure of $267 \pm 17$ bar. For most of the test, water was injected into the autoclave at a rate of $4.5 \mathrm{~g} / \mathrm{min}$. The density of water under these test conditions was $0.0675 \mathrm{~g} / \mathrm{cm}^{3}$, with a resulting water velocity at test conditions of $2.1 \mathrm{~mm} / \mathrm{min}$.

The atmospheric pressure test was programmed to mimic the time and temperature profile of the high pressure test. The test medium was steam with $10 \% \mathrm{Ar}$, flowing at a rate of $25 \mathrm{~cm} / \mathrm{min}$ (at temperature). The Ar carrier gas helped to prevent backflow of air from the water condensing exit line during temperature fluctuations in the furnace.

Data collected included mass change measurements, scanning electron microscopy (SEM) of the surfaces and cross-sections of exposed samples using back-scattered electrons (BSE), and microanalysis using wavelength dispersive spectroscopy (WDS).

\section{Results and Discussion}

Mass change data for the high pressure and atmospheric pressure tests are shown in Fig. 4. The error bars on the high pressure data show the standard deviation from triplicate samples. In all cases the high pressure mass gains were higher than at atmospheric pressure. 

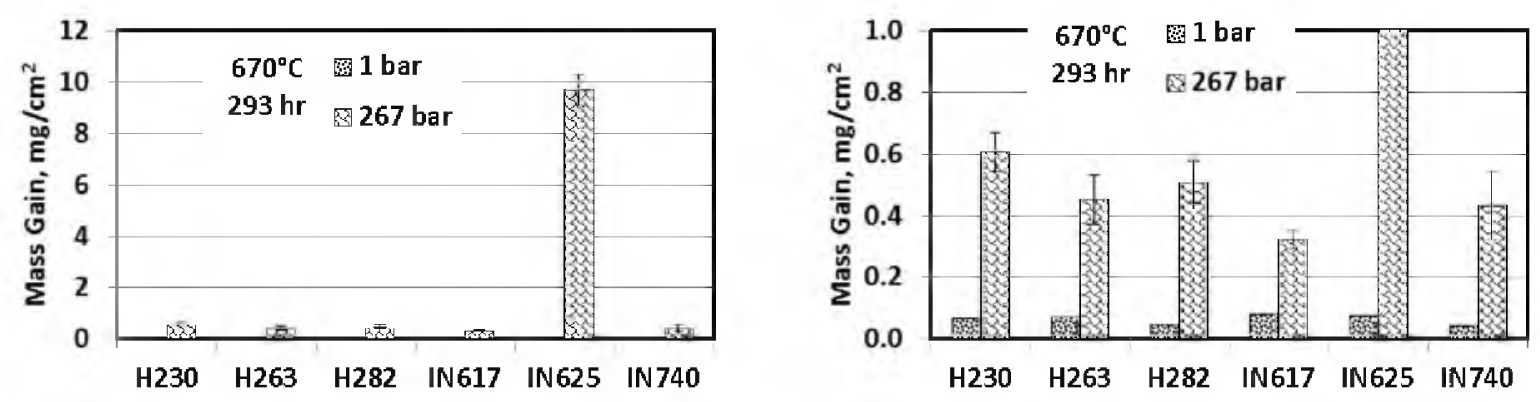

Figure 4. Mass gain results after $293 \mathrm{hr}$ at $670^{\circ} \mathrm{C}$ for high pressure and atmospheric pressure steam oxidation exposures. The plot on the right shows the same data as on the left but with an expanded scale.

Table III shows the mass gain data in tabular form, as well as expressed in parabolic rate constant, $\mathrm{k}_{\mathrm{p}}$, form using Eq. 1, where $\mathrm{t}$ is time.

$$
\mathrm{k}_{\mathrm{p}}=\frac{(\text { mass gain })^{2}}{2 \mathrm{t}}
$$

Table III. Mass gain and parabolic rate constants from $293 \mathrm{hr}$ exposures at $670^{\circ} \mathrm{C}$ in steam.

\begin{tabular}{|c|c|c|c|c|c|}
\hline \multirow{2}{*}{ Alloy } & \multicolumn{2}{|c|}{ Mass gain, $\mathrm{mg} / \mathrm{cm}^{2}$} & \multicolumn{2}{|c|}{$k_{p}, g^{2} / \mathrm{cm}^{4} / s$} & \multirow{2}{*}{$\begin{array}{l}\mathrm{k}_{\mathrm{p}} \text { factor } \\
\text { increase }\end{array}$} \\
\hline & $1 \mathrm{bar}$ & $267 \mathrm{bar}$ & $1 \mathrm{bar}$ & $267 \mathrm{bar}$ & \\
\hline $\mathrm{H} 230$ & 0.069 & $0.61 \pm 0.06$ & $2.26 \times 10^{-15}$ & $1.74 \times 10^{-13}$ & 77 \\
\hline $\mathrm{H} 263$ & 0.072 & $0.45 \pm 0.08$ & $2.49 \times 10^{-15}$ & $9.73 \times 10^{-14}$ & 39 \\
\hline $\mathrm{H} 282$ & 0.050 & $0.51 \pm 0.07$ & $1.19 \times 10^{-15}$ & $1.23 \times 10^{-13}$ & 100 \\
\hline IN617 & 0.083 & $0.32 \pm 0.03$ & $3.31 \times 10^{-15}$ & $4.94 \times 10^{-14}$ & 15 \\
\hline IN625 & 0.078 & $9.69 \pm 0.62$ & $2.89 \times 10^{-15}$ & $4.46 \times 10^{-11}$ & 15,000 \\
\hline IN740 & 0.046 & $0.43 \pm 0.11$ & $1.02 \times 10^{-15}$ & $8.90 \times 10^{-14}$ & 87 \\
\hline
\end{tabular}

Even though these initial tests have not established that parabolic behavior occurred, they were put into parabolic form for ease of comparison with literature values for these and similar alloys (shown later).

Cross-sections are shown in Figs. 5-6. All six of the 1 bar cross-sections show a thin, dense and compact scale that is presumably chromia — but too thin for accurate SEM microanalysis.

The oxide scales at 267 bar are thicker, and much thicker in the case of IN625. Table IV shows elemental maps of $\mathrm{Cr}$ and $\mathrm{O}$ for 267 bar exposures. Alloys $\mathrm{H} 230$ and $\mathrm{H} 282$ have thin ribbons of high $\mathrm{Cr}$ oxide within the scale. Alloys $\mathrm{H} 263$ and IN740 have a layer of high $\mathrm{Cr}$ oxide near the metal-scale interface, and alloy IN617 has high Cr oxide throughout. The oxide scale for IN625 has overall metal ratios close to that of the alloy. There are ribbons of higher $\mathrm{Cr}$ content similar to those found in the much thinner scales on $\mathrm{H} 230$ and $\mathrm{H} 282$. The thicker scales for these alloys, as compared to the 1 bar exposure, corresponds to the mass gain behavior shown in Fig. 4 . 

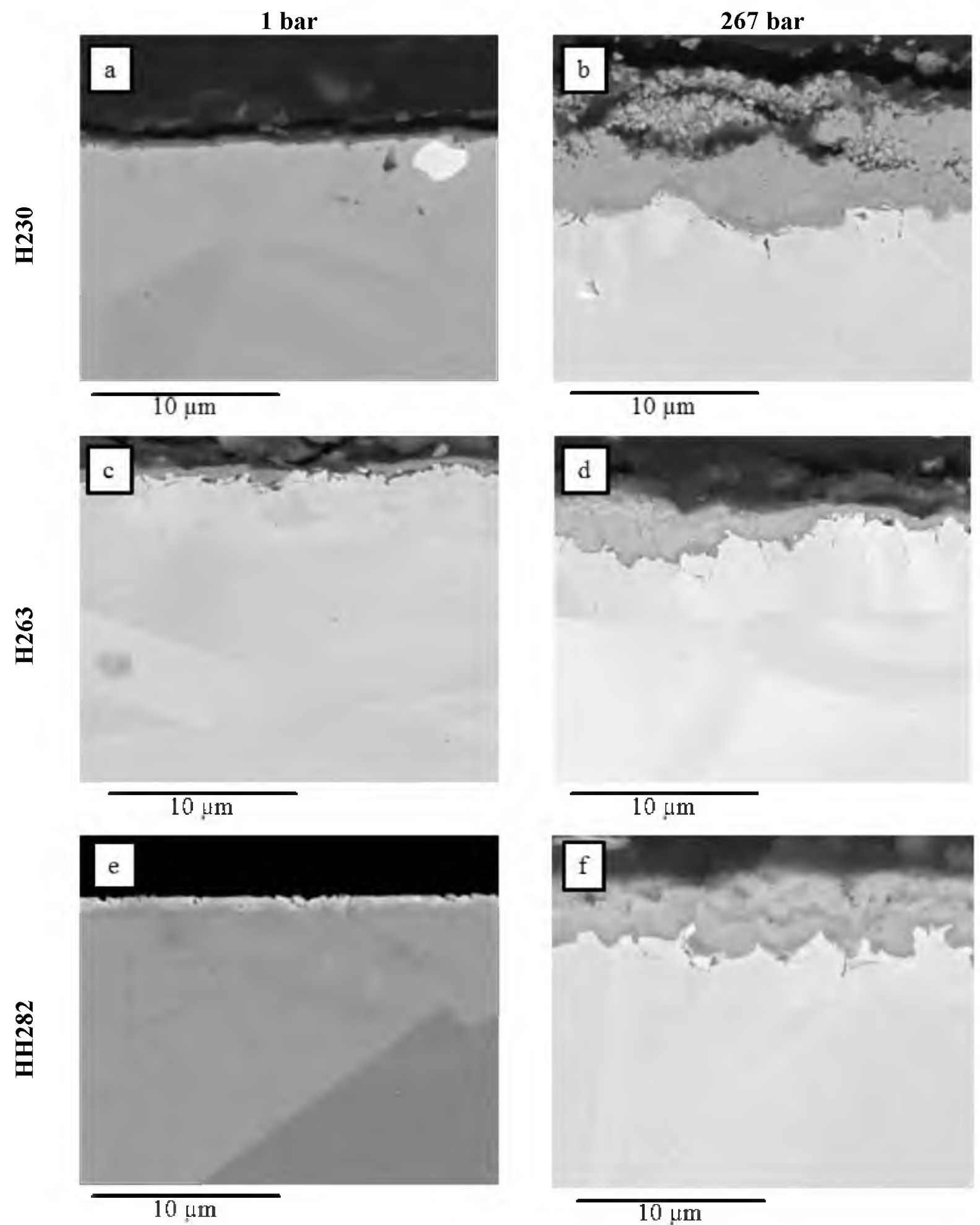

Figure 5. BSE cross-section images of $\mathrm{H} 230, \mathrm{H} 263$, and $\mathrm{H} 282$ after $293 \mathrm{hr}$ exposure at $670^{\circ} \mathrm{C}$ in steam 

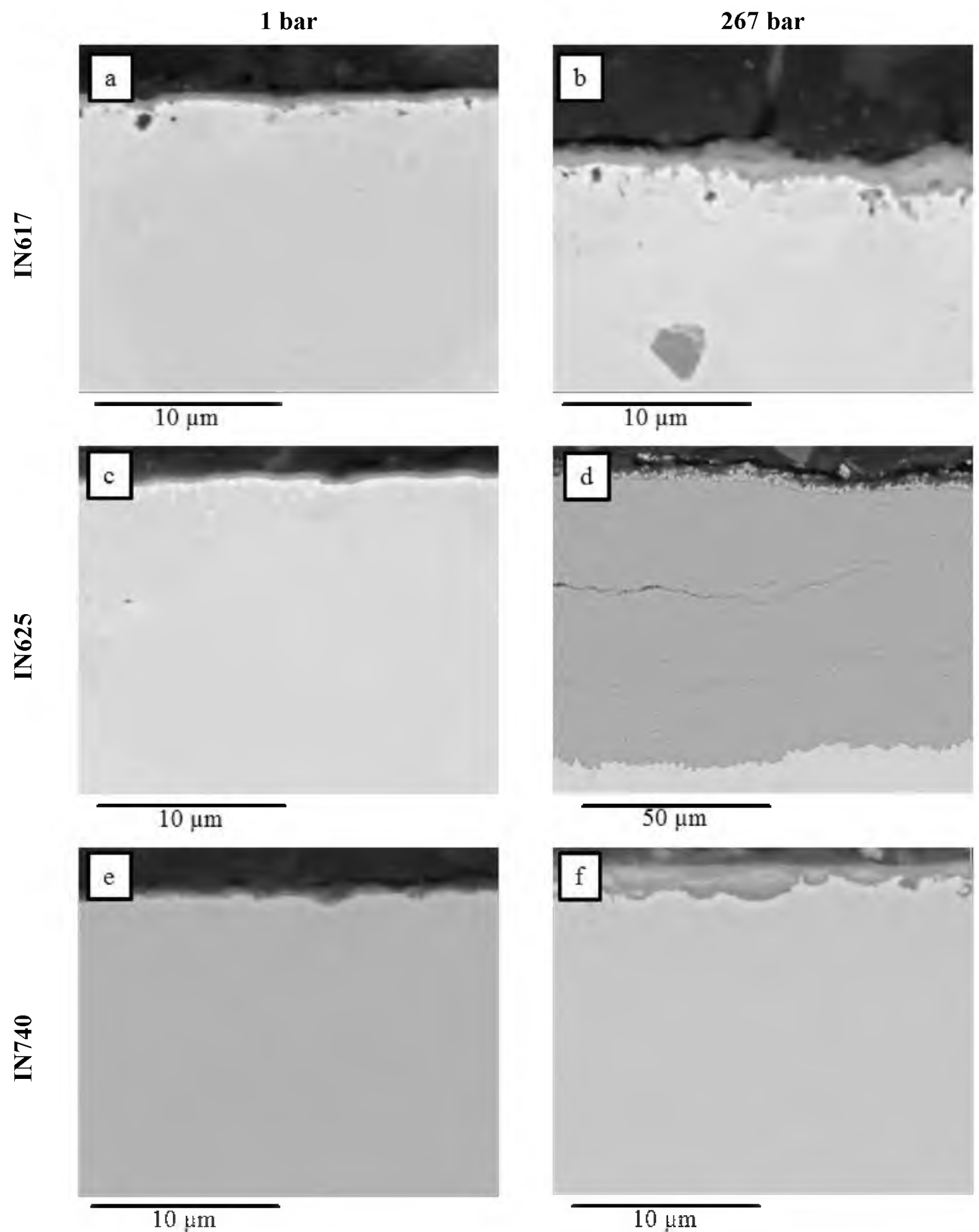

Figure 6. BSE cross-section images of IN617, IN625, and IN740 after $293 \mathrm{hr}$ exposure at $670^{\circ} \mathrm{C}$ in steam. 
Table IV. Scale morphologies and maps of $\mathrm{Cr}$ and $\mathrm{O}$ after $293 \mathrm{hr}$ exposure at $670^{\circ} \mathrm{C}$ and $267 \mathrm{bar}$ in steam.

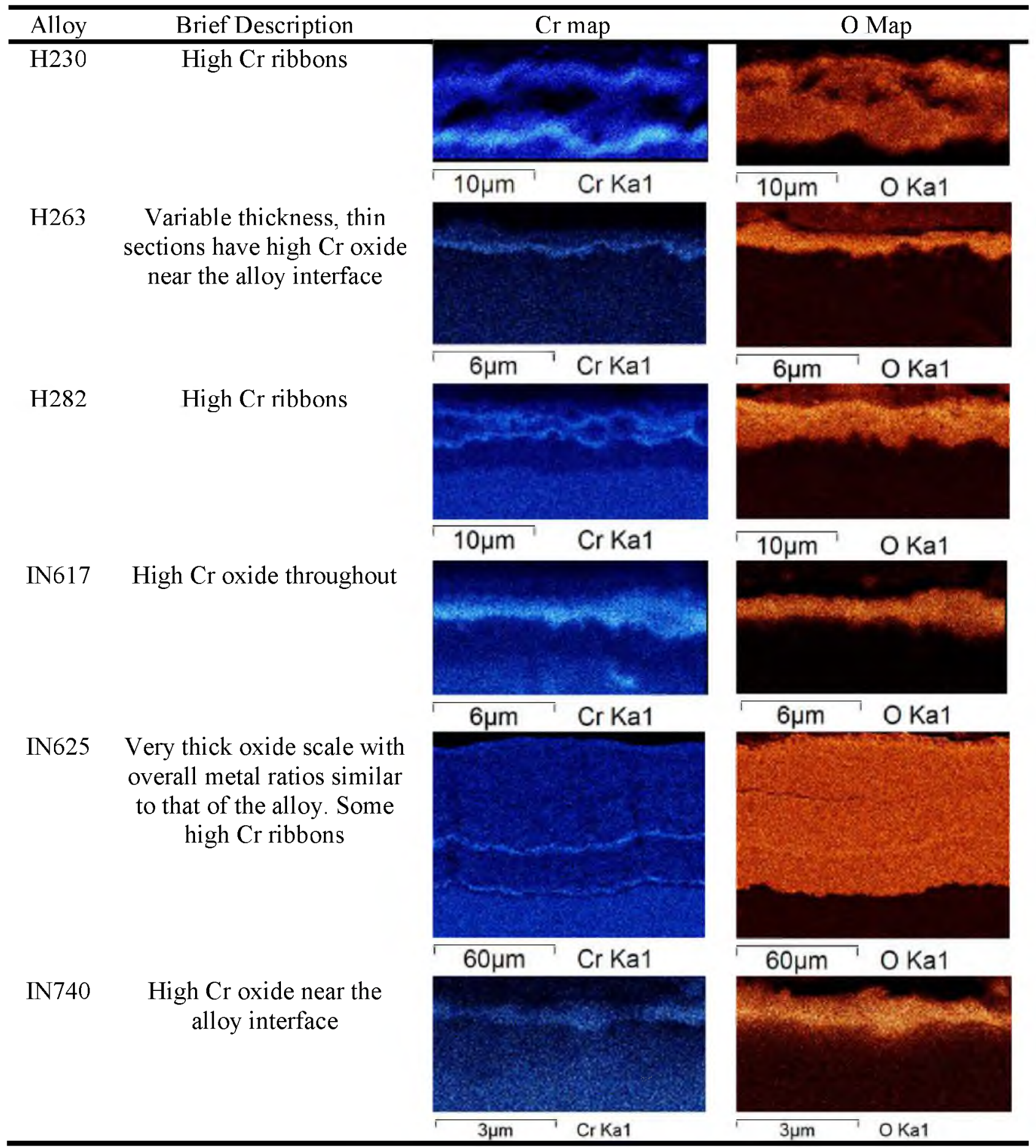

A comparison with the parabolic rates for these experimental results with those in the literature for Ni-base alloys is shown in Fig. 7. Most of the points for exposures with pressures of 105 bar or less fall along or near the PMCr line associated with a pure chromia scale. The 1 bar test experiments followed this trend, and the thin, dense and compact scales are consistent with a pure chromia scale. The exception to this trend is the data point at 41 bar and $750^{\circ} \mathrm{C}$ [4], which is well above the trend line. However, this data point is for $\mathrm{IN600}$, which has a lower $\mathrm{Cr}$ content $(16.3 \mathrm{wt} \%)$ [4] than the other alloys in Fig. 7. All but one of the data points at 241 bar or higher 
follow another trend line with a similar slope (activation energy) but about two orders of magnitude higher. The exception is the test experiment for IN625, which was about two orders of magnitude higher than the other 267 bar test experiments.

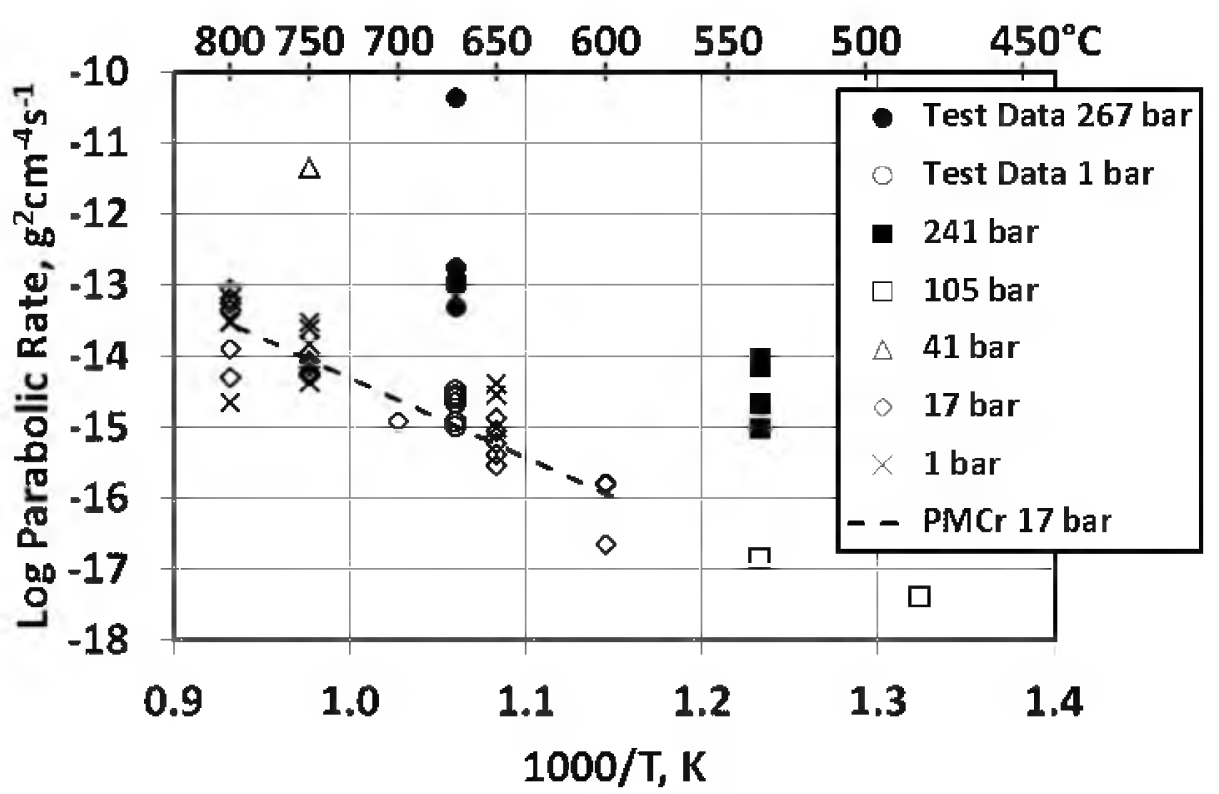

Figure 7. Arrhenius plot of parabolic oxidation of Ni-base alloys in steam, adapted from the compilation of Wright and Dooley [5] from numerous sources: 241 bar (IN600, IN601, IN718) [6], 105 bar (IN617) [7], 41 bar (IN600) [4], 17 bar (H230, IN617, IN718, IN740, Nim263, Nim80A, PMCr) [8], and 1 bar (H230, IN617, IN740, and Nim263) [9].

\section{$\underline{\text { IN625 }}$}

The grain sizes of the six alloys were measured to see if grain size could be contributing to the high oxidation rates of IN625. The ASTM grain sizes varied widely: H263 with 2, IN740 with 3, IN617 with 5, and both $\mathrm{H} 230$ and IN625 with 6 . The grain structure of H282 was duplex, with sizes of 3 and 7. The small grain size in the IN625 alloy should aid and not hinder the establishment of a chromia scale.

A comparison of the composition of IN625 with the other alloys (Table II) shows a Cr content in the middle of the range, a Mo content similar to H282 and IN617, lower Co and A1 levels, and higher $\mathrm{Fe}, \mathrm{Nb}$, and $\mathrm{Cu}$ levels. While lower, $\mathrm{Al}$ at $0.2 \mathrm{wt} \%$ is not much different than that of $\mathrm{H} 230$ or H263. A Calphad-type of analysis was done on the alloys using ThermoCalc [10] and the Ni-8 database [11]. The results for IN625 using the alloy composition in Table II (with the inclusion of $0.05 \mathrm{C}$ ) are shown in Table V. The phases are the matrix face centered cubic (FCC) phase gamma, the $\mathrm{Ni}_{3} \mathrm{Nb}$ phase delta, the topologically close packed (TCP) phase $\mathrm{mu}$, and the carbide $\mathrm{M}_{23} \mathrm{C}_{6}$. The gamma and $\mathrm{M}_{23} \mathrm{C}_{6}$ phases are common to all six of the alloys. The mu phase is also present in $\mathrm{H} 263, \mathrm{H} 282$, and IN617. Only the delta phase is unique to IN625 as the other alloys do not have sufficient $\mathrm{Nb}$ to form delta. However, $\mathrm{Cr}$ is not concentrated in delta, so this phase does not reduce the $\mathrm{Cr}$ available for chromia formation. 
Table V. Calphad-type analysis of IN625 at $700^{\circ} \mathrm{C}$ for phases and element distributions, wt $\%$.

\begin{tabular}{cccccccccccccc}
\hline Phase & $\mathrm{Fe}$ & $\mathrm{Cr}$ & $\mathrm{Ni}$ & $\mathrm{Co}$ & $\mathrm{Mo}$ & $\mathrm{Si}$ & $\mathrm{Ti}$ & $\mathrm{Al}$ & $\mathrm{Mn}$ & $\mathrm{Nb}$ & $\mathrm{Cu}$ & $\mathrm{C}$ & $\begin{array}{c}\text { Mass } \\
\text { Fraction }\end{array}$ \\
\hline Alloy & 4.4 & 21.4 & 61.2 & 0.1 & 8.4 & 0.3 & 0.3 & 0.2 & 0.1 & 3.3 & 0.3 & 0.05 & \\
$\begin{array}{c}\text { Gamma } \\
\text { FCC }\end{array}$ & 5.3 & 22.8 & 64.1 & 0.1 & 4.6 & 0.4 & 0.2 & 0.2 & 0.1 & 0.8 & 0.4 & & 0.809 \\
$\begin{array}{c}\text { Delta } \\
\mathrm{Ni}_{3} \mathrm{Nb}\end{array}$ & 0.1 & 0.2 & 66.4 & & 2.0 & & 1.6 & 0.2 & & 29.4 & & & 0.090 \\
$\mathrm{Mu}$ & 0.9 & 24.5 & 27.2 & & 47.3 & & & & & & & & 0.091 \\
$\begin{array}{c}\mathrm{TCP} \\
\mathrm{Carbide} \\
\mathrm{M}_{23} \mathrm{C}_{6}\end{array}$ & 0.4 & 69.5 & 4.9 & & 20.0 & & & & & & & 5.1 & 0.010 \\
\hline
\end{tabular}

\section{Effect of Pressure on Oxidation Kinetics}

Increases in pressure are expected to directly change oxidation kinetics based on increases in solid state diffusion in the oxide scale. Following the treatment of Wright and Dooley [5], the pressure dependence on diffusion (and thus the parabolic rate constant) can be described by:

$$
\mathbf{k}_{\mathrm{p}} \propto \mathbf{P}_{\mathrm{T}}^{\left(\frac{2}{3}\right)\left(\frac{\mathrm{b}}{2 \mathrm{a}(\alpha+1)}\right)}=\mathbf{P}_{\mathrm{T}}^{\mathrm{X}}
$$

Where $\mathrm{P}_{T}$ is the total pressure and $\alpha$ is the effective charge on the metal vacancies in a $\mathrm{M}_{\mathrm{a}} \mathrm{O}_{\mathrm{b}}$ oxide. The $2 / 3$ term arises from the increased partial pressure of $\mathrm{O}_{2}$ in steam with increasing pressure. The other term arises from the assumption of oxide growth being controlled by the outward diffusion of metal ions in a metal deficit type electronic semiconductor. $\mathrm{For}_{\mathrm{Fe}} \mathrm{O}_{4}, \alpha$ is either 2 or 3 ; for $\mathrm{Cr}_{2} \mathrm{O}_{3}, \alpha$ is 3 . Applying this assumption for chromia is not always valid. In some cases chromia scales grow from inward diffusion of oxygen rather than outward diffusion of $\mathrm{Cr}$ - such as when small additions of oxygen active elements like $\mathrm{Hf}$ and $\mathrm{Zr}$ are added to the alloy [12]. And there are other cases when simultaneous counter-current diffusion of $\mathrm{Cr}$ and $\mathrm{O}$ occur. $\mathrm{X}$ in Eq. 2 is the overall pressure dependence exponent. Table VI summarizes this treatment of pressure effects.

Table VI. Summary of oxidation kinetics increases due to increased diffusion in the oxide scale, for representative pressure differences.

\begin{tabular}{cccccc}
\hline \multirow{2}{*}{$\Delta \mathrm{P}_{\mathrm{T}}$, bar } & \multicolumn{2}{c}{ Magnetite $(\mathrm{X}=0.11-0.15)$} & & \multicolumn{2}{c}{ Chromia $(\mathrm{X}=0.13)$} \\
\cline { 2 - 3 } \cline { 5 - 6 } & $\begin{array}{c}\mathrm{k}_{\mathrm{p}} \text { factor } \\
\text { increase }\end{array}$ & $\begin{array}{c}\text { Scale thickness } \\
\text { increase, } \%\end{array}$ & & $\begin{array}{c}\mathrm{k}_{\mathrm{p}} \text { factor } \\
\text { increase }\end{array}$ & $\begin{array}{c}\text { Scale thickness } \\
\text { increase, } \%\end{array}$ \\
\hline 1 to 267 & $1.9-2.3$ & $36-51$ & & 2.0 & 42 \\
1 to 345 & $1.9-2.4$ & $38-54$ & & 2.1 & 44 \\
165 to 345 & $1.09-1.12$ & $5.6-8.2$ & & 1.1 & 6.5 \\
20 to 126 & $1.2-1.3$ & $13-18$ & & 1.3 & 15 \\
\hline
\end{tabular}

In Table VI, a $\Delta \mathrm{P}_{\mathrm{T}}$ from 1 to 267 bar (the experimental conditions) predicts a kp increase by a factor of 2.0 for chromia. This is much smaller than the factor increases in Table III for the experimental results. 
Included in Table VI are values associated with the A-USC targets (from Table I, 345 bar is the top target pressure and 165 is a representative subcritical pressure). $\mathrm{A} \Delta \mathrm{P}_{\mathrm{T}}$ from 20 to $126 \mathrm{bar}$ are the pressure differences that Paterson et al. [7] reported for a service comparison of T22 superheater (126 bar) and reheater (20 bar) boiler tubes. A pressure exponent of 0.20 was reported-somewhat higher than the 0.11-0.15 for magnetite in Table VI.

The increases in oxidation due to increased solid state diffusion in the oxide scale are insufficient to explain the results. Other contributing factors have been proposed:

- Paterson et al. [13] suggested that differences in stress levels (from pressure) may influence oxidation, as well as the presence of larger thermal gradients at high pressures (superheater tubing compared with reheater tubing).

- For ferritic steels in boilers, Montgomery and Karlsson [14] observed increased porosity with increased pressure, and suggest that if thermal conductivity increases with porosity, then higher metal temperatures will occur for the same steam temperature. Thus pressure increases may indirectly lead to higher temperatures and higher oxidation rates.

- Wright and Dooley [5] suggested that increased dissolution of impurities, such as silica, with increased pressure may contribute to increased oxidation rates.

Another way of attributing the large effect of increased pressure on increased oxidation is by an increased critical $\mathrm{Cr}$ content required to form and maintain a protective chromia scale. Some observations to support this are:

- In the experimental tests, IN625 underwent an increase in $\mathrm{k}_{\mathrm{p}}$ by a factor of 15,000 , Table III. A large increase in scale thickness accompanied this change. A change from a protective chromia scale to a less protective spinel-type scale occurred.

- At 267 bar, the oxide scales of alloys H230 and H282 showed ribbons with high Cr levels (Table IV). The presence of these ribbons of high Cr levels is suggestive of cycles of establishing and then breaking down of protective chromia scales.

- In Fig. 7, an anomalous data point was IN600 at 41 bar and $750^{\circ} \mathrm{C}$. The alloy had a $\mathrm{Cr}$ content of $16.3 \mathrm{wt} \%$ - smaller than the rest of the alloys. IN600 at 41 bar performed much like the higher $\mathrm{Cr}$ alloys at 241 bar and above.

A methodology to describe various factors that contribute to a critical $\mathrm{Cr}$ content $\left(\mathrm{N}_{\mathrm{Cr}}\right)$ is shown in Eq. 3 for establishment of a chromia scale, $\mathrm{N}_{\mathrm{Cr}}{ }^{(1)}$, and $\mathrm{Eq} .4$ for maintaining a chromia scale, $\mathrm{N}_{\mathrm{Cr}}{ }^{(2)}$, in M-Cr alloys [15-16].

$$
\begin{gathered}
\mathrm{N}_{\mathrm{Cr}}^{(1)}>\left(\frac{\pi \mathrm{g}^{*}}{3} \mathrm{~N}_{\mathrm{O}}^{(\mathrm{S})} \frac{\mathrm{D}_{\mathrm{O}} \mathrm{V}_{\mathrm{m}}}{\dot{\mathrm{D}}_{\mathrm{M}-\mathrm{Cr}} \mathrm{V}_{\mathrm{CrO}_{1.5}}}\right)^{\frac{1}{2}} \\
\mathrm{~N}_{\mathrm{Cr}}^{(2)}>\frac{V_{m}}{48}\left(\frac{\pi k_{p}}{\dot{\mathrm{D}}_{\mathrm{M}-\mathrm{Cr}}}\right)^{\frac{1}{2}}
\end{gathered}
$$

Where $\mathrm{N}_{\mathrm{O}}{ }^{(\mathrm{s})}$ is the oxygen solubility in the alloy, $\mathrm{D}_{\mathrm{O}}$ is the diffusivity of oxygen in the alloy, $\dot{\mathrm{D}}_{\mathrm{M}-\mathrm{Cr}}$ is the alloy interdiffusion coefficient, and $\mathrm{V}_{\mathrm{m}}$ and $\mathrm{V}_{\mathrm{CrO1.5}}$ are the molar volumes of the alloy and oxide, respectively. The factor $\mathrm{g}^{*}$ is generally approximated as 0.3 . 
The temperature dependences in Eqs. 3-4 are the inverse of each other. At low temperatures maintaining a chromia scale determines $\mathrm{N}_{\mathrm{Cr}}$ (Eq. 4), while at high temperatures establishing a chromia scale determines $\mathrm{N}_{\mathrm{Cr}}$ (Eq. 3). For Ni-Cr alloys, the switch-over temperature is expected

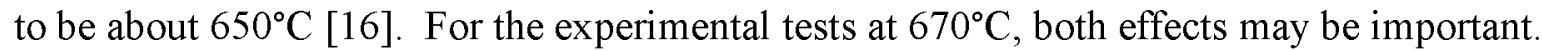

Essuman et al. [17] and Ani et al. [18] both report that hydrogen dissolution, as a product of oxidation by water vapor, can increase oxygen permeability in $\mathrm{Fe}-\mathrm{Cr}$ alloys. In terms of Eq. 3, oxygen permeability is the product $\mathrm{N}_{\mathrm{O}}{ }^{(\mathrm{s})} \mathrm{D}_{\mathrm{O}}$. The partial pressure of $\mathrm{H}_{2}$ will increase with increasing total pressure in the same manner that the partial pressure of $\mathrm{O}_{2}$ increases-by a factor of $\mathrm{P}_{\mathrm{T}}{ }^{2 / 3}$ [5]. One would expect higher $\mathrm{H}_{2}$ partial pressures to increase the amount of hydrogen dissolution into the metal, thus making chromia formation harder and increasing the critical $\mathrm{Cr}$ level. In terms of maintaining a chromia scale, higher $\mathrm{k}_{\mathrm{p}}$ values from higher solid state diffusion in the oxide (Eq. 2), will increase the critical $\mathrm{Cr}$ level to maintain a chromia scale (Eq. 4). When translated to Ni-Cr alloys, both of these effects could explain some of the increases in oxidation rates at high pressures, and the observed oxide scale thicknesses and morphologies.

\section{Conclusions}

A 1 liter autoclave, rated to $346 \mathrm{bar} / 704^{\circ} \mathrm{C}$ and $228 \mathrm{bar} / 760^{\circ} \mathrm{C}$, was constructed and a steam oxidation test was conducted at $267 \pm 17$ bar and $670^{\circ} \mathrm{C}$ for $293 \mathrm{hr}$. It was a flowing steam system with a water velocity within the autoclave of $2.1 \mathrm{~mm} / \mathrm{min}$. A comparison test was run at 1 bar. Results for triplicate samples at various locations within the autoclave showed no position dependence. Parabolic rate constants, $\mathrm{k}_{\mathrm{p}}$, were estimated from the data and compared with literature values from much longer duration tests

Ni-base alloys at 1 bar all formed a thin chromia scale, all with low oxidation rates. At 267 bar, five of the alloys (H230, H263, H282, IN617 and IN740) had increased scale thickness and $\mathrm{k}_{\mathrm{p}}$ values a factor of one-to-two orders of magnitude higher than at $1 \mathrm{bar}$. The 1 bar data matched literature values for chromia, while the 267 bar data appeared to establish a trend line on an Arrhenius plot with similar activation energy to chromia but at a higher oxidation rate.

Alloy IN625 had a four order of magnitude increase in $k_{p}$ at 267 bar compared to 1 bar, and the scale was very thick and had metal ratios similar to that of the alloy. Grain size, composition, and expected phases were examined as possible sources of the difference between IN625 and the other alloys, but no conclusions were established.

Possible causes for increased oxidation rates with increased pressure were examined. Increased solid state diffusion within the oxide scale is quantifiable and accounts for a modest increases in expected corrosion rate and scale thickness. This can also lead to an increase in the critical $\mathrm{Cr}$ content to maintain a chromia scale. Increased amounts of hydrogen in the alloy, injected into the metal during steam oxidation, can increase oxygen permeability and thus lower the ability of the alloy to establish a chromia scale-an increase in the critical $\mathrm{Cr}$ content for chromia scales. 


\section{Acknowledgements}

This work was funded by the U. S. DOE Cross-cutting Technologies program at the National Energy Technology Laboratory. This report was prepared as an account of work sponsored by the United States Government. Neither the United States Government nor any agency thereof, nor any of their employees, makes any warranty, express or implied, or assumes any legal liability or responsibility for the accuracy, completeness, or usefulness of any information, apparatus, product, or process disclosed, or represents that its use would not infringe privately owned rights. Reference herein to any specific commercial product, process, or service by trade name, trademark, manufacturer, or otherwise does not necessarily constitute or imply its endorsement, recommendation, or favoring by the United States Government or any agency thereof.

\section{References}

1. Richard Dennis, "The DOE Turbine Program: Overall Program Description," The Gas Turbine Handbook, Chapter 6.0.1 (National Energy Technology Laboratory, 2006), http://www.netl.doe.gov/technologies/coalpower/turbines/refshelf/handbook/6.0.1.pdf

2. "U.S. Department of Energy and Ohio Coal Development Office Advanced Ultra-Supercritical Materials Project for Boilers and Steam Turbines: Summary of Results" (Report 1022770, EPRI, March 2011).

3. R. Viswanathan, A. F. Armor, and G. Booras, "A Critical Look at Supercritical Power Plants," Power, 148(3)(2004), 42-49.

4. W. E. Ruther, R. R. Schlueter, R. H. Lee, R. K. Hart, "Corrosion Behavior of Steels and Nickel Alloys in Superheated Steam," Corrosion, 22 (1965), 147-155.

5. I. G. Wright and R. B. Dooley, "A Review of the Oxidation Behaviour of Structural Alloys in Steam," International Materials Reviews, 55 (3)(2010), 129-167.

6. H. E. McCoy and B. McNabb, "Corrosion of Several Metals in Supercritical Steam at $538^{\circ}$ C" (Report ORNL/TM-5781, Oak Ridge National Laboratory, 1977).

7. J. C. Griess, J. M. Devan and W. A. Maxwell, "Effect of a high heat flux on the corrosion of 2.25Cr-1Mo steel in superheated steam," Materials Performance, 17(1)(1978), 9-15.

8. I. G. Wright, P. F. Tortorelli, M. Schütze, "Oxide Growth and Exfoliation on Alloys Exposed to Steam" (Report 1013666, EPRI, 2007).

9. J. Sarver, private communication from J. Sarver, Babcock \& Wilcox, to I. Wright, Oak Ridge National Laboratory, 2009.

10. Thermo-Calc, "An Application for Thermodynamic Calculations," Version 3.1, Foundation of Computational Thermodynamics, Stockholm, Sweden, 2013

11. N. Saunders, "Ni-DATA," Version 8, Thermotech Ltd, Surrey Technology Centre, Surrey, UK (2009) 
12. Per Kofstad, High Temperature Corrosion (New York, NY: Elsevier Applied Science,1988), $400-402$.

13. R. Paterson, R. Moser and T. R. Rettig, "Oxidation of Boiler Tubing," Proc. EPRI-VGB Int. Conf. on Interaction of Iron-based Materials with Water and Steam, eds. R. B. Dooley and A. Bursik (Heidelberg, Germany, Report TR-102101, 8-1-8-5, EPRI, June 1992).

14. M. Mongomery and A. Karlsson, "Survey of Oxidation in Steamside Conditions," VGB Kraftswerkstechnik, 75 (3)(1995), 235-240.

15. G. H. Meier, K. Jung, N. Mu, N. M. Yanar, F. S. Pettit, J. Pirón Abellán, T. Olszewski, W. J. Quadakkers, and G. R. Holcomb, "Effect of Alloy Composition and Exposure Conditions on the Selective Oxidation Behavior of Ferritic Fe-Cr and Fe-Cr-X Alloys," Oxidation of Metals, 74 (56)(2010), 319-340.

16. N. Mu, K. Y. Jung, N. M. Yanar, F. S. Pettit, G. R. Holcomb , B. H. Howard, and G. H. Meier, "The Effects of Water Vapor and Hydrogen on the High-Temperature Oxidation of Alloys," Oxidation of Metals, 79(5-6)(2013), 461-472.

17. E. Essuman, G. H. Meier, J. Żurek, M. Hänsel, L. Singheiser, and W. J. Quadakkers, "Enhanced Internal Oxidation as Trigger for Breakaway Oxidation of Fe-Cr Alloys in Gases Containing Water Vapor," Scripta Materialia, 57 (9)(2007), 845-848.

18. M. H. B. Ani, T. Kodama, M. Ueda, K. Kawamura, and T. Maruyama, "The Effect of Water Vapor on High Temperature Oxidation of Fe-Cr Alloys at 1073K," Materials Transactions, 50 (11)(2009), 2656-2663. 